\title{
Alteração de parâmetros químicos do solo pela reaplicação superficial de calcário no sistema plantio direto(1)
}

\begin{abstract}
Antonio Sergio do Amaral(2) e Ibanor Anghinoni(3)
Resumo - A aplicação superficial de calcário está se tornando uma prática comum de correção da acidez do solo no sistema plantio direto no Sul do Brasil. O objetivo desta pesquisa foi avaliar o efeito da reaplicação de calcário, com e sem incorporação ao solo no sistema plantio direto, sobre as características químicas das fases sólida e líquida ao longo do tempo e do perfil do solo. O experimento foi conduzido em solo Argissolo Vermelho distrófico típico, cultivado há oito anos no sistema plantio direto com reaplicação de calcário a cada quatro anos. Em outubro de 1996, foram aplicadas, em toda

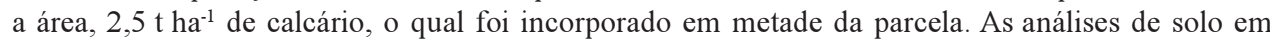
camadas de $1 \mathrm{~cm}$ de espessura, em curtos espaços de tempo, permitiram verificar efeitos relativamente rápidos da reaplicação de calcário na superfície do solo em profundidade. O maior efeito da dissolução do calcário ocorreu aos 90 dias de sua reaplicação. Os efeitos em profundidade se manifestaram a partir dos 180 dias da reaplicação; atingiram, aos 360 dias, até $2 \mathrm{~cm}$ quanto aos teores de $\mathrm{Ca}$ e $\mathrm{Mg}$ na solução do solo, e até $4 \mathrm{~cm}$ quanto ao $\mathrm{pH}$ em $\mathrm{CaCl}_{2}$ e aos teores de $\mathrm{Al}, \mathrm{Ca}$ e $\mathrm{Mg}$ trocáveis.
\end{abstract}

Termos para indexação: solução do solo, $\mathrm{pH}$ do solo, condutividade elétrica, calagem.

Changes in chemical characteristics of the soil profile by surface lime application in no-tillage system

\begin{abstract}
Surface lime application is becoming an usual practice for soil acidity correction in the established no-tillage system in Southern Brazil. The objective of this study was to evaluate the effects of lime reapplication, with and without incorporation into the soil on chemical characteristics of the liquid and solid phase, in the soil profile at different periods. A field experiment was set up in a Rhodic Paleudult soil under no-tillage system with lime reapplication every four years. Lime ( 2.5 ton ha $\left.{ }^{-1}\right)$ was then applied (October, 1996) after the eighth year and, as previously done in 1992, incorporated into the soil in half of each of the tillage plots. Soil analysis in $1 \mathrm{~cm}$ soil layers in short time periods showed relatively fast effects of surface lime application in changing the chemical characteristics in the soil profile. Maximum lime dissolution effects occurred after 90 days of lime reapplication. The effects in the soil depth occurred after 180 days of lime reapplication, and reached after 360 days $2 \mathrm{~cm}$ for Ca and $\mathrm{Mg}$ content in soil solution and $4 \mathrm{~cm}$ for $\mathrm{pH}\left(\mathrm{CaCl}_{2}\right)$ and exchangeable $\mathrm{Al}, \mathrm{Ca}$ and $\mathrm{Mg}$.
\end{abstract}

Index terms: soil solution, soil $\mathrm{pH}$, electrical conductivity, liming.

(1) Aceito para publicação em 19 de junho de 2000.

Extraído da dissertação de mestrado apresentada pelo primeiro autor à Universidade Federal do Rio Grande do Sul (UFRGS), Porto Alegre, RS. Apoio financeiro: PRONEX-FINEP.

(2)UFRGS, Caixa Postal 776, CEP 90001-970 Porto Alegre, RS E-mail: asamaral@hotmail.com

(3)UFRGS, Faculdade de Agronomia, Dep. de Solos. Bolsista do CNPq. E-mail: ibanghi@vortex.ufrgs.br

\section{Introdução}

O não-revolvimento do solo no sistema plantio direto e o conseqüente acúmulo de resíduos vegetais, corretivos e fertilizantes na sua superfície promovem modificações nas características químicas do solo em relação ao sistema convencional. Estas modificações ocorrem de forma gradual e progressiva a 
partir da superfície do solo, e afetam tanto a disponibilidade de nutrientes quanto o processo da acidificação do solo (Sidiras \& Pavan, 1985; Rheinheimer et al., 1998).

As recomendações de calagem em uso no Sul do Brasil foram elaboradas dentro das técnicas convencionais de preparo de solo e envolvem a completa mobilização da camada arável, para uma melhor reação do corretivo com o solo. Esta é uma questão que vem preocupando técnicos e produtores que trabalham com o sistema plantio direto no Brasil, tendo em vista que o revolvimento do solo não permite a manutenção da qualidade do solo (agregação, espaço poroso e infiltração de água) nesse sistema. Assim, constata-se que a maioria dos produtores vem adotando a prática de reaplicar o calcário sem incorporá-lo ao solo. Entretanto, há carência de dados da pesquisa para recomendar métodos de aplicação de calcário mais adequados ao sistema plantio direto.

O conhecimento da dinâmica da acidez a partir da superfície do solo, no sistema plantio direto, ao longo do tempo, é necessário para estabelecer ajustes na recomendação de calagem e na freqüência de reaplicação do corretivo. A reacidificação, processo que ocorre naturalmente no solo, se manifesta de forma diferenciada no sistema plantio direto. A decomposição de resíduos culturais e o uso de adubos nitrogenados depositados na superfície do solo provoca uma intensa acidificação da camada superficial, formando um gradiente de $\mathrm{pH}$ a partir da superfície, chamado de frente de acidificação (Blevins et al., 1977, 1983). No Brasil, não se têm detectado aumentos significativamente diferenciados na acidez a partir da superfície do solo no sistema plantio direto (Muzilli, 1983; Sidiras \& Pavan, 1985; Silva, 1996; Burle et al., 1997), o que pode ser atribuído à aplicação de doses relativamente baixas de adubos nitrogenados e a períodos relativamente curtos de avaliação.

Existem indicativos de que a correção da acidez em profundidade, no sistema plantio direto com aplicação de calcário superficial, ocorre em menor tempo do que o esperado, considerando-se a baixa solubilidade do calcário e a sua não-incorporação ao solo (Cassol, 1995; Pöttker \& Ben, 1998). Porém, esses efeitos são mais difíceis de serem detectados quando se analisa somente a fase sólida e camadas espessas de solo $(5-10 \mathrm{~cm})$, e quando decorridos maiores períodos de tempo após a aplicação do calcário.

O objetivo deste trabalho foi avaliar os efeitos da reaplicação do calcário, com e sem sua incorporação ao solo, no sistema plantio direito, sobre as características químicas das fases sólida e líquida ao longo do tempo e do perfil do solo.

\section{Material e Métodos}

O experimento foi instalado na Estação Experimental Agronômica da Universidade Federal do Rio Grande do Sul (EEA/UFRGS), no Município de Eldorado do Sul, RS, região fisiográfica da Depressão Central A precipitação média anual é de $1.440 \mathrm{~mm}$, e o clima da região, segundo a classificação de Köppen, é o subtropical de verão úmido quente ( $\mathrm{Cfa}$ ). O solo, de textura francoargilosa e origem granítica, é classificado como Argissolo Vermelho distrófico típico (Embrapa, 1999). O local do experimento apresenta relevo ondulado a suave ondulado.

Em maio de 1988, foi aplicado calcário dolomítico, na dose de 3,4 t ha $\mathrm{t}^{-1}$ (PRNT 100\%), para elevar o $\mathrm{pH}$ em água a 6,0 (método SMP). O calcário foi incorporado até $17 \mathrm{~cm}$ de profundidade, por meio de uma aração e duas gradagens, seguido do cultivo de aveia forrageira (Avena strigosa $\mathrm{S}$.) para manter o solo coberto. Em setembro, a aveia foi dessecada com herbicida, e em outubro foram aplicados os tratamentos de preparo de solo nas parcelas, e realizouse a semeadura do milho (Zea mays L.), seguida de um novo cultivo de aveia forrageira. Essa seqüência de cultivos (milho, no verão, e aveia forrageira, no inverno) foi utilizada anualmente.

Em 1992, após quatro anos da instalação, o experimento recebeu a primeira reaplicação de calcário $\left(3,7 \mathrm{tha}^{-1}\right.$ PRNT 100\%, método SMP para $\mathrm{pH} 6,0)$, sendo as parcelas (preparo do solo) divididas em duas partes: incorporação do calcário ao solo em uma metade da parcela, e nãoincorporação na outra metade. O experimento foi conduzido com a seqüência milho-aveia forrageira, por mais quatro anos. Em outubro de 1996, aplicou-se novamente o calcário dolomítico, na dose de 2,5 t ha-1 (PRNT 100\% para elevar o $\mathrm{pH}$ do solo até 6,0 método SMP), incorporado e não incorporado nas respectivas subparcelas. O calcário utilizado apresentava PRNT 103,4\%, com teores de $\mathrm{Ca}$ e $\mathrm{Mg}$ de $30,2 \%$ e $20,2 \%$, respectivamente, e $95,11 \%$ das partículas menores do que $0,3 \mathrm{~mm}$ (peneira 50 mesh). A adubação, a lanço, utilizada para o cultivo do milho na safra 96/97 foi de $110 \mathrm{~kg} \mathrm{ha}^{-1}$ de $\mathrm{P}_{2} \mathrm{O}_{5}$, e de 
$60 \mathrm{~kg} \mathrm{ha}^{-1}$ de $\mathrm{K}_{2} \mathrm{O}$ nas formas de superfosfato triplo e cloreto de potássio, respectivamente. A adubação nitrogenada $\left(150 \mathrm{~kg} \mathrm{ha}^{-1}\right.$ de $\left.\mathrm{N}\right)$ foi dividida em três frações - aos 20, 40 e 60 dias após a emergência do milho aplicando-se, em cada uma, $50 \mathrm{~kg} \mathrm{ha}^{-1} \mathrm{de} \mathrm{N}$, na forma de uréia. Foram realizadas cinco amostragens de solo: aos 30 (5/11/96), 60 (5/12/96), 90 (5/1/97), $180(5 / 4 / 97)$ e 360 $(5 / 10 / 97)$ dias após a reaplicação de calcário, nas camadas de $0-1,0,1,0-2,0,2,0-3,0,3,0-4,0$ e $4,0-5,0$ cm de profundidade. As amostras de solo foram coletadas com pá-de-corte, sendo compostas por quatro subamostras com as dimensões de $16 \mathrm{~cm}$ de largura, $3 \mathrm{~cm}$ de espessura e $1 \mathrm{~cm}$ de profundidade. Foram analisadas as fases sólida e líquida do solo. $\mathrm{Na}$ fase sólida, foram determinados $\mathrm{pH}$ $\mathrm{CaCl}_{2}$ 0,01 mol L-1 (relação 1:1) com eletrodo de vidro, conforme descrito em Embrapa (1997); Ca e Mg trocáveis $\left(\mathrm{KCl} 1 \mathrm{~mol} \mathrm{~L}^{-1}\right)$, por espectrofotometria de absorção atômica; $\mathrm{Al}$ trocável $\left(\mathrm{KCl} 1 \mathrm{~mol} \mathrm{~L}^{-1}\right)$, por titulação com $\mathrm{NaOH}$ $0,0125 \mathrm{~mol} \mathrm{~L}^{-1}$, e indicador de azul de bromotimol, conforme descrito em Tedesco et al. (1995).

A extração da solução do solo foi realizada segundo descrito por Elkhatib et al. (1987) e adaptada por Fernandes (1989). Na solução do solo foram determinados o $\mathrm{pH}$ com eletrodo de vidro, a condutividade elétrica (CE) com condutivímetro, e os teores de $\mathrm{Ca}$ e $\mathrm{Mg}$ por absorção atômica, conforme descrito em Tedesco et al. (1995)

O modelo estatístico utilizado para a análise de variância foi

$\mathrm{Y}_{\mathrm{ijkl}}=\mathrm{m}+\mathrm{Bi}+\mathrm{Ij}+$ erro a(ij) $+\mathrm{C}_{\mathrm{k}}+$ erro b(ik) $+\mathrm{IC}_{\mathrm{jk}}+$ erro c(ijk) $+\mathrm{T}_{1}+$ erro d(il) $+\mathrm{IT}_{\mathrm{j} 1}+$ erro e $(\mathrm{ijl})+\mathrm{CT}_{\mathrm{kl}}+$ erro $\mathrm{f}(\mathrm{ikl})+\mathrm{ICT}_{\mathrm{jkl}}+$ erro g(ijkl),

onde:

$\mathrm{B}=$ bloco, $\mathrm{I}=$ incorporação do calcário, $\mathrm{C}=$ camada de solo, $\mathrm{T}=$ tempo, $\mathrm{i}=1,2,3 ; \mathrm{j}=1,2 ; \mathrm{k}=1,2, \ldots, 5 \mathrm{el}=1,2, \ldots, 5$.

Para a comparação de médias foi utilizado o teste de Tukey $(\mathrm{P}<0,05)$

\section{Resultados e Discussão}

Os valores de $\mathrm{pH}$ e os demais atributos químicos, das fases sólida e líquida, foram, como esperado, mais uniformes quando o calcário foi incorporado, e formaram gradientes a partir da superfície quando não foi incorporado. Os valores mais altos de $\mathrm{pH}$ na superfície (camada de 0-1 cm), quando o calcário não foi incorporado, pouco se alteraram no tempo (Figura 1). A partir da segunda camada, houve somente uma tendência de aumento gradativo $(\mathrm{P}<0,05)$, tanto no $\mathrm{pH}$ da solução do solo como em $\mathrm{CaCl}_{2}$ 0,01 mol L-1. Para ambas as medidas, houve interação $(\mathrm{P}<0,05)$ entre incorporação e profundidade (Tabela 1). Os efeitos do calcário aplicado superficialmente são, então, detectados no perfil do solo, tanto pelo $\mathrm{pH}$ na solução como pelo $\mathrm{pH}$ em $\mathrm{CaCl}_{2}$, e ocorreram até a profundidade de $4 \mathrm{~cm}$.

Os valores de $\mathrm{Al}$ trocável se mantiveram mais baixos na superfície do solo ao longo do período de avaliação, quando o calcário não foi incorporado ao solo (Figura 1). Da mesma forma, a partir da segunda camada, houve apenas uma tendência de aumento gradativo nesses valores $(\mathrm{P}<0,05)$ no tempo. O mesmo comportamento não ocorreu quando o calcário foi incorporado. Neste caso, após uma fase inicial de diminuição, que ocorreu entre 60 e 90 dias da aplicação, os teores de $\mathrm{Al}$ aumentaram com o tempo, atingindo valores elevados, após 360 dias da aplicação do calcário, especialmente nas camadas superiores (0-1 e 1-2 cm).

As diferenças resultantes da incorporação, ou não, do calcário, a exemplo do que ocorreu com o pH, somente se manifestaram $(\mathrm{P}<0,05)$ em relação à profundidade (Tabela 1). Enquanto os teores de Al se mantiveram uniformes e mais elevados pela incorporação do calcário, aumentaram em profundidade pela não-incorporação, diferenciando-se entre si a partir da camada de 3-4 cm.

A manutenção do $\mathrm{pH}$ mais elevado, até a camada de 2-3 cm, pela não-incorporação do calcário justifica os menores teores de Al trocável (Tabela 1). Redução do Al trocável na camada de $0-5 \mathrm{~cm}$, aos 12 meses após a aplicação superficial de $3,6 \mathrm{tha}^{-1} \mathrm{de}$ calcário, no sistema plantio direto, também foi verificada por Santos (1997). A intensidade de neutralização do $\mathrm{Al}$ em profundidade depende da quantidade de calcário aplicada. Pöttker \& Ben (1998), comparando diferentes doses de calcário aplicadas na superfície de um Latossolo Vermelho distrófico típico e de um Latossolo Vermelho distroférico típico, obtiveram, em ambos os solos, redução do Al trocável, principalmente na camada de $0-5 \mathrm{~cm}$, e, em menor grau, na camada de $5-10 \mathrm{~cm}$, quando utilizaram as doses de 1 SMP e $1 / 2 \operatorname{SMP}(10,7$ e 7,2 $\mathrm{t} \mathrm{ha}^{-1}$, respectivamente).

Os efeitos da dissolução do calcário nas diferentes camadas do solo no tempo podem ser visualizados pelos resultados das análises da condutividade elétrica (Figura 1), em que ocorreu interação tripla $(\mathrm{P}<0,05)$. Houve um aumento inicial dos valores até os 90 dias da aplicação do calcário, e depois, uma 

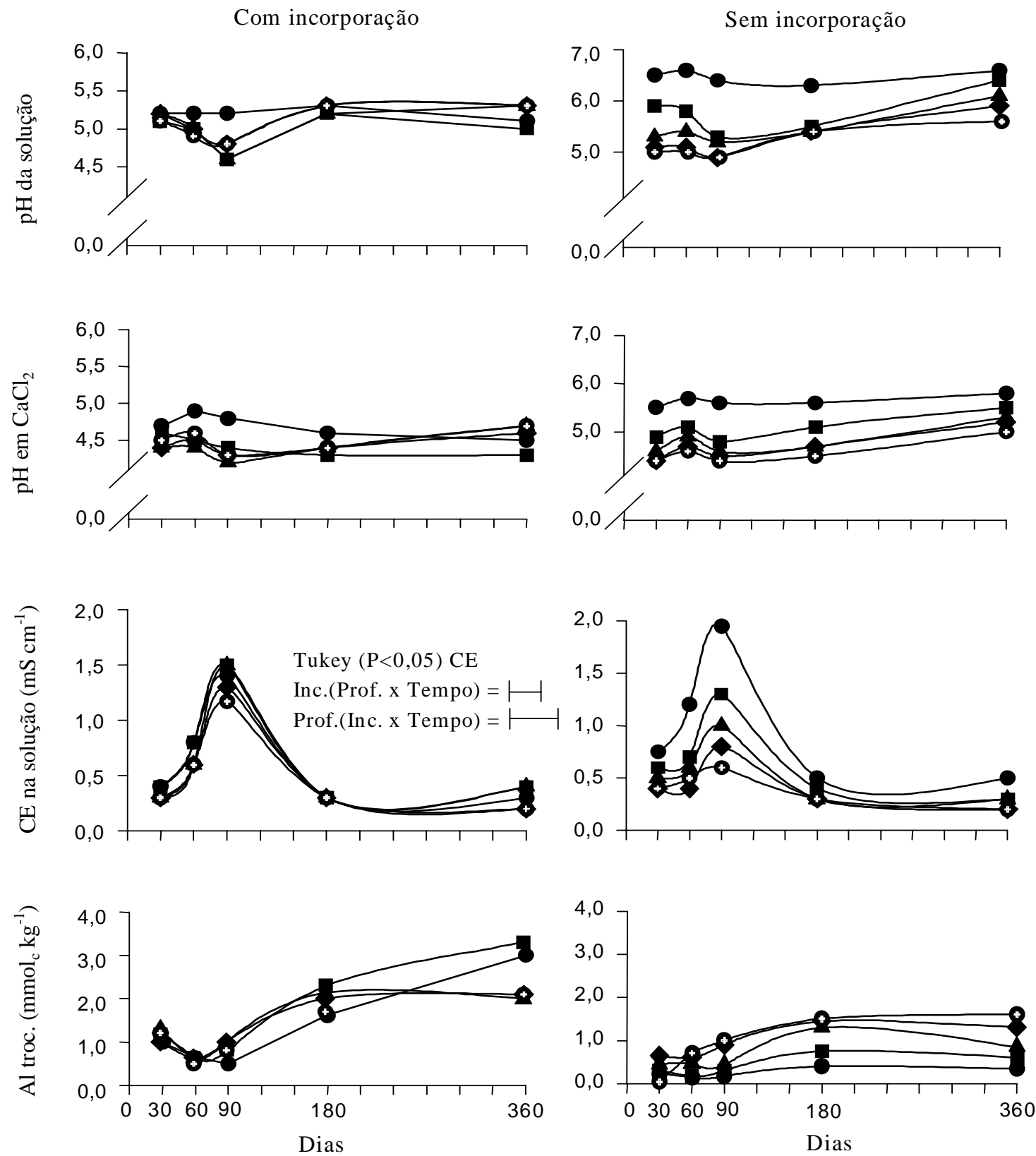

\begin{tabular}{|c|}
\hline$-0-1 \mathrm{~cm} \quad-1-2 \mathrm{~cm} \quad-2-3 \mathrm{~cm} \quad-3-4 \mathrm{~cm} \quad-4-5 \mathrm{~cm}$ \\
\hline
\end{tabular}

Figura 1. Valores de $\mathrm{pH}$ na solução do solo e na fase sólida $\left(\mathrm{CaCl}_{2} 0,01 \mathrm{M}\right)$, de condutividade elétrica $(\mathrm{CE})$ e de alumínio trocável, nas diferentes camadas de solo, aos 30,60, 90, 180 e 360 dias após a aplicação de calcário, com e sem incorporação. Dados médios de três repetições. 
Tabela 1. Valores de $\mathrm{pH}$, cálcio, magnésio e alumínio, nas diferentes camadas de solo, após a aplicação de calcário, com e sem incorporação ao solo. Dados médios de três repetições $^{(1)}$.

\begin{tabular}{|c|c|c|c|c|}
\hline \multirow{2}{*}{$\begin{array}{c}\text { Camada } \\
(\mathrm{cm})\end{array}$} & \multicolumn{4}{|c|}{ Incorporação de calcário } \\
\hline & Com & Sem & Com & Sem \\
\hline & \multicolumn{2}{|c|}{------- pH na solução ------- } & \multicolumn{2}{|c|}{------ pH em $\mathrm{CaCl}_{2}$} \\
\hline $0-1$ & $5,17 \mathrm{aB}$ & $6,49 \mathrm{aA}$ & $4,66 \mathrm{aB}$ & $5,64 \mathrm{aA}$ \\
\hline $1-2$ & $5,07 \mathrm{aB}$ & $5,78 \mathrm{bA}$ & $4,55 \mathrm{abB}$ & $5,08 \mathrm{bA}$ \\
\hline $2-3$ & $5,06 \mathrm{aB}$ & $5,48 \mathrm{cA}$ & $4,43 \mathrm{bB}$ & $4,82 \mathrm{cA}$ \\
\hline $3-4$ & $5,05 \mathrm{aB}$ & $5,29 \mathrm{cA}$ & $4,43 \mathrm{bB}$ & $4,70 \mathrm{cdA}$ \\
\hline \multirow[t]{2}{*}{$4-5$} & $5,02 \mathrm{aB}$ & $5,19 \mathrm{cB}$ & $4,40 \mathrm{bB}$ & $4,58 \mathrm{~dB}$ \\
\hline & \multicolumn{2}{|c|}{$\begin{array}{l}\text {---- Cálcio na solução ------ } \\
\left(\mathrm{mmol}_{\mathrm{c}} \mathrm{dm}^{-3}\right)\end{array}$} & \multicolumn{2}{|c|}{$\begin{array}{l}\text {----- Cálcio trocável ------ } \\
\left(\mathrm{mmol}_{\mathrm{c}} \mathrm{kg}^{-1}\right)\end{array}$} \\
\hline $0-1$ & $1,87 \mathrm{aB}$ & $4,55 \mathrm{aA}$ & $34,25 \mathrm{aB}$ & $63,81 \mathrm{aA}$ \\
\hline $1-2$ & $2,32 \mathrm{aA}$ & $2,55 \mathrm{bA}$ & $33,23 \mathrm{aB}$ & $47,72 \mathrm{bA}$ \\
\hline $2-3$ & $1,99 \mathrm{aA}$ & $2,30 \mathrm{bA}$ & $33,28 \mathrm{aB}$ & $39,26 \mathrm{cA}$ \\
\hline $3-4$ & $1,77 \mathrm{aA}$ & $2,02 \mathrm{bA}$ & $35,07 \mathrm{aA}$ & $36,20 \mathrm{dA}$ \\
\hline \multirow[t]{2}{*}{$4-5$} & $1,65 \mathrm{aA}$ & $2,03 \mathrm{bA}$ & $34,64 \mathrm{aA}$ & $34,87 \mathrm{dA}$ \\
\hline & \multicolumn{2}{|c|}{$\begin{array}{l}\text {----Magnésio na solução ---- } \\
\left(\mathrm{mmol}_{\mathrm{c}} \mathrm{dm}^{-3}\right)\end{array}$} & \multicolumn{2}{|c|}{$\begin{array}{l}\text {----Alumínio trocável ---- } \\
\left(\mathrm{mmol}_{\mathrm{c}} \mathrm{kg}^{-1}\right)\end{array}$} \\
\hline $0-1$ & $1,31 \mathrm{aB}$ & $2,82 \mathrm{aA}$ & $1,36 \mathrm{aA}$ & $0,25 \mathrm{cB}$ \\
\hline $1-2$ & $1,66 \mathrm{aA}$ & $1,46 \mathrm{bA}$ & $1,81 \mathrm{aA}$ & $0,41 \mathrm{bcB}$ \\
\hline $2-3$ & $1,55 \mathrm{aA}$ & $1,23 \mathrm{bA}$ & $1,46 \mathrm{aA}$ & $0,73 \mathrm{abcB}$ \\
\hline $3-4$ & $1,37 \mathrm{aA}$ & $1,07 \mathrm{bA}$ & $1,52 \mathrm{aA}$ & $1,00 \mathrm{abB}$ \\
\hline $4-5$ & $1,41 \mathrm{aA}$ & $0,98 \mathrm{bA}$ & $1,27 \mathrm{aB}$ & $1,26 \mathrm{aA}$ \\
\hline
\end{tabular}

${ }^{(1)}$ Valores de cada parâmetro com as mesmas letras, minúsculas na coluna e maiúsculas na linha, não diferem entre si pelo teste de Tukey a $5 \%$ de probabilidade.

diminuição no tempo. Entretanto, enquanto os valores não se diferenciaram nas diversas camadas do solo pela incorporação do calcário, eles foram maiores nas camadas superficiais, pela não-incorporação do calcário ao solo. Neste caso, a condutividade elétrica reflete a concentração dos cátions dominantes na solução do solo, a qual é decorrente do efeito direto do calcário e dos adubos empregados. Assim, embora não-significativo $(\mathrm{P}<0,05)$ na interpretação tripla, o comportamento do $\mathrm{Ca}$ e $\mathrm{Mg}$ na solução do solo é similar ao da condutividade elétrica, bem como nos respectivos valores trocáveis (Figura 2), com interação tripla significativa em relação ao $\mathrm{Mg}$ trocável. Maiores valores de CE pela adição de corretivo ao solo também foram observados por Lima (1993) e Bissani (1997). A calagem, além de adicionar os íons $\mathrm{Ca}$ e $\mathrm{Mg}$ à solução do solo, também promove aumento na mineralização da matéria orgânica e aumento da capacidade de troca de cátions, contribuindo para o aumento da concentração dos ânions em solução (Lima, 1993).

A máxima dissolução do calcário ocorreu aos 90 dias de sua aplicação ao solo, com diferenciação até a camada de 3-4 $\mathrm{cm}$ pela manutenção do calcário na superfície (Figura 1). É provável que, na ocasião, a força iônica da solução do solo tenha sido suficiente para provocar, por efeito salino, a diminuição do pH observado na Figura 1. Partículas de diferentes tamanhos, presentes no calcário, apresentam diferenças de eficiência com o decorrer do tempo de avaliação (Zancanaro, 1996). Pandolfo \& Tedesco (1996) observaram que num Argissolo Vermelho distrófico típico as partículas de diâmetro entre 0,10 e 0,25 e 0,84 e $2,00 \mathrm{~mm}$ apresentaram estabilização dos valores de $\mathrm{pH}$ aos 6 e 42 meses, respectivamente. No presente trabalho, o calcário utilizado apresentava $95,11 \%$ de partículas menores do que $0,3 \mathrm{~mm}$, sendo estas, provavelmente, as que, após o contato com o solo ácido, se dissolveram rapidamente na presença de umidade adequada.

Diferenças $(\mathrm{P}<0,05)$ no efeito em profundidade, pela incorporação, ou não, do calcário (interação), foram detectadas em relação ao $\mathrm{Ca}$ e $\mathrm{Mg}$ na solução, e em relação ao Ca trocável (Tabela 1). Enquanto os valores foram mais uniformes pela incorporação do calcário, eles foram maiores na superfície pela nãoincorporação do calcário, chegando a se diferenciar até a camada de 2-3 cm em relação ao Ca trocável.

Os valores de $\mathrm{pH}$ e $\mathrm{Al}$ trocável revelam que no sistema plantio direto, quando não há incorporação do calcário, ocorre uma frente de neutralização da acidez a partir da superfície do solo. Isto tem sido atribuído ao movimento descendente das partículas finas de calcário, quando as características físicas são favoráveis, como no sistema plantio direto, ou ao movimento, por fluxo de massa, dos ânions básicos $\left(\mathrm{OH}^{-}\right.$ e $\mathrm{HCO}_{3}^{-}$) resultantes da dissolução do calcário. Entretanto, é possível, também, que esteja ocorrendo a complexação do $\mathrm{Al}$ trocável por ligantes orgânicos hidrossolúveis liberados dos resíduos e da matéria orgânica acumulada na superfície do solo no sistema plantio direto (Pavan et al., 1984; Miyazawa et al., 1992; Pavan, 1997; Salet, 1998).

Considerando a baixa solubilidade do calcário, os efeitos da sua aplicação superficial ocorreram de forma bastante rápida. Observam-se aumentos de $\mathrm{Ca} \mathrm{e}$ $\mathrm{Mg}$ em profundidade e no tempo, semelhantemente ao observado quanto ao $\mathrm{pH}$, e inversamente em relação ao Al trocável. É possível que o comportamento dos teores destes atributos, no tratamento sem mobilização do solo, não seja apenas decorrente da 


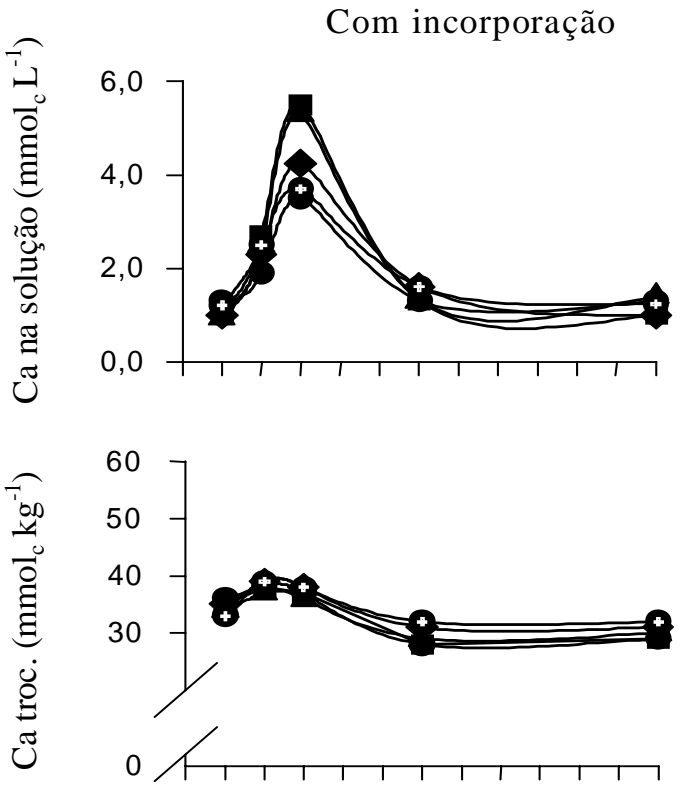

Sem incorporação
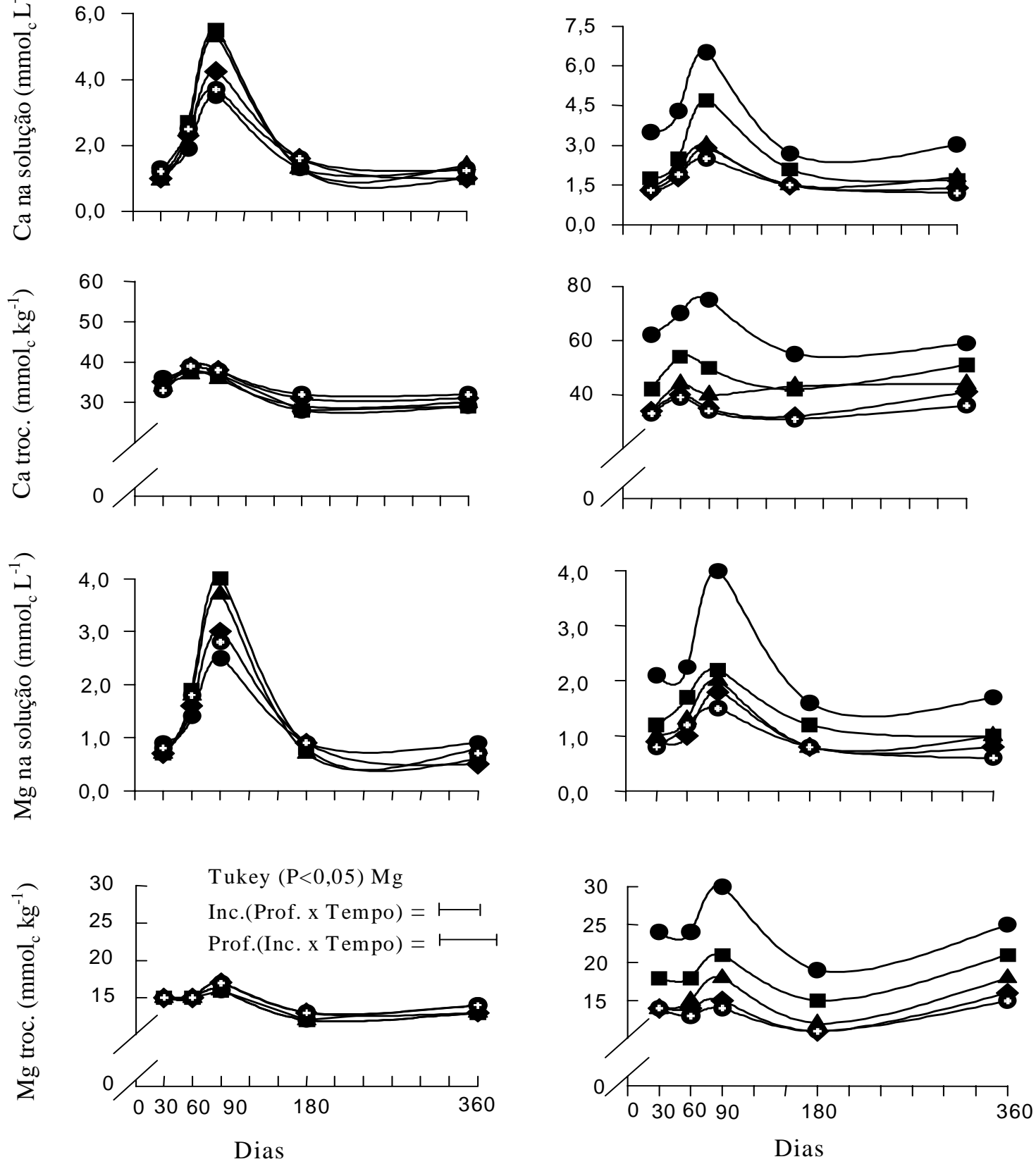

$\multimap-0-1 \mathrm{~cm} \quad 1-2 \mathrm{~cm} \quad-2-3 \mathrm{~cm} \quad-\quad-3 \mathrm{~cm} \quad-\boldsymbol{-}-4 \mathrm{~cm}$

Figura 2. Valores de cálcio e magnésio na solução do solo e na fase sólida, nas diferentes camadas de solo, aos 30, 60, 90, 180 e 360 dias após a aplicação de calcário, com e sem incorporação. Dados médios de três repetições. 
última reaplicação de calcário ocorrida em 1996, mas também, do efeito acumulado da primeira reaplicação de calcário efetuada em 1992.

A interpretação dos dados obtidos pela avaliação das características químicas em camadas de $1 \mathrm{~cm}$ a partir da superfície do solo mostra que, em apenas 90 dias após a aplicação do calcário superficial, já se verificam efeitos tanto na fase sólida como na fase líquida do solo em até $3 \mathrm{~cm}$ de profundidade. Tais efeitos foram observados tanto no aumento dos constituintes do calcário (Ca e Mg), como na neutralização da acidez do solo ( $\mathrm{pH}$ e $\mathrm{Al}$ ), o que indica que existe uma importante frente de alcalinização a partir da superfície do solo, no sistema plantio direto consolidado.

\section{Conclusões}

1. Os valores do $\mathrm{pH}$ da solução do solo e em $\mathrm{CaCl}_{2}$ $0,01 \mathrm{~mol} \mathrm{~L}^{-1}$ não se alteram na camada de $0-1 \mathrm{~cm}$ ao longo do tempo, porém, nas outras camadas até $4 \mathrm{~cm}$ verifica-se aumento do $\mathrm{pH}$, principalmente a partir dos 180 dias.

2. A aplicação de calcário na superfície altera até a profundidade de $4 \mathrm{~cm}$ os valores de $\mathrm{pH}, \mathrm{Al}, \mathrm{Ca} \mathrm{e}$ $\mathrm{Mg}$ trocáveis, e os valores de $\mathrm{Ca}$ e $\mathrm{Mg}$ na solução, até $2 \mathrm{~cm}$, aos 360 dias após a sua aplicação.

3. A dissolução máxima de calcário ocorre aos 90 dias de sua aplicação, conforme indicam os valores de condutividade elétrica e de $\mathrm{Ca}$ e $\mathrm{Mg}$ na solução do solo.

\section{Referências}

BISSANI, C. Redução dos efeitos da acidez do solo pela aplicação de carbonato e sulfato de cálcio em superfície. Porto Alegre : UFRGS, 1997. 107 p. Dissertação de Mestrado.

BLEVINS, R. L.; THOMAS, G. W.; CORNELIUS, P. L. Influence of no-tillage and nitrogen fertilization on certain soil properties after 5 years of continuous corn. Agronomy Journal, Madison, v. 69, p. 383-386, 1977.

BLEVINS, R. L.; THOMAS, G. W.; SMITH, M. S Changes in soil properties after 10 of years continuous non-tillage and conventionally tilled corn. Soil and Tillage Research, Amsterdam, v. 3, p. 135-146, 1983

BURLE, M. L.; MIELNICZUK, J.; FOCCHI, S. Effect of cropping systems on soil chemical characteristics, with emphasis on soil acidification. Plant and Soil, Dordrecht, v. 190, p. 309-316, 1997.

CASSOL, L. C. Características físicas e químicas do solo e rendimento de culturas após a reaplicação de calcário, com e sem incorporação, em sistemas de preparo. Porto Alegre : UFRGS, 1995. 97 p. Dissertação de Mestrado.

ELKHATIB, E. A.; HERN, J. L.; STALEY, T. E. A rapid centrifugation method for obtaining soil solution. Soil Science Society of America Journal, Madison, v. 51, n. 3, p. $578-583,1987$.

EMBRAPA. Centro Nacional de Pesquisa de Solos (Rio de Janeiro, RJ). Manual de métodos de análise de solo 2. ed. Rio de Janeiro, 1997. 247 p.

EMBRAPA. Centro Nacional de Pesquisa de Solos (Rio de Janeiro, RJ). Sistema brasileiro de classificação de solos. Brasília : Embrapa-SPI, 1999. 412 p.

FERNANDES, F. F. Fatores relacionados à acidez de solos e sua influência, no desenvolvimento e absorção de cálcio, magnésio, manganês e alumínio por feijão e milho. Porto Alegre : UFRGS, 1989. 117 p. Dissertação de Mestrado.

LIMA, M. R. Dinâmica de nutrientes em função da calagem de solos arenosos. Porto Alegre : UFRGS, 1993. 112 p. Dissertação de Mestrado.

MIYAZAWA, M.; CHIERICE, G. O.; PAVAN, M. A. Amenização da toxicidade de alumínio as raízes do trigo pela complexação com ácidos orgânicos. Revista Brasileira de Ciência do Solo, Campinas, v. 16, p. 209-215, 1992.

MUZILLI, O. Influência do sistema de plantio direto, comparado ao convencional, sobre a fertilidade da camada arável do solo. Revista Brasileira de Ciência do Solo, Campinas, v. 7, p. 317-322, 1983.

PANDOLFO, C. M.; TEDESCO, M. J. Eficiência relativa de frações granulométricas de calcário na correção da acidez do solo. Pesquisa Agropecuária Brasileira, Brasília, v. 31, n. 10, p. 753-758, out. 1996.

PAVAN, M. A. Ciclagem de nutrientes e mobilidade de íons no solo sob plantio direto. Revista Plantio Direto, Passo Fundo, v. 41, p. 8-12, 1997.

PAVAN, M. A.; BINGHAM, F. T.; PRATT, P. F. Redistribution of exchangeable calcium, magnesium, and aluminum following lime or gypsum applications to a Brazilian oxisol. Soil Science Society of America Journal, Madison, v. 48, n. 1, p. 33-38, 1984. 
PÖTTKER, D.; BEN, J. R. Calagem para uma rotação de culturas no sistema plantio direto. Revista Brasileira de Ciência do Solo, Campinas, v. 22, p. 675-684, 1998.

RHEINHEIMER, D. S.; KAMINSKI, J.; LUPATINI, G. C.; SANTOS, E. J. S. Modificações em atributos químicos de solo arenoso sob sistema plantio direto. Revista Brasileira de Ciência do Solo, Campinas, v. 22, p. 713 721,1998

SALET, R. L. Toxidez de alumínio no sistema plantio direto. Porto Alegre : UFRGS, 1998. 109 p. Tese de Doutorado.

SANTOS, E. J. S. Aplicação de calcário em solos arenosos sob sistema plantio direto e campo nativo. Santa Maria : UFSM, 1997. 67 p. Dissertação de Mestrado.
SIDIRAS, N.; PAVAN, M. A. Influência do sistema de manejo do solo no seu nível de fertilidade. Revista Brasileira de Ciência do Solo, Campinas, v. 9, p. 249-254, 1985.

SILVA, L. S. Características químicas de um latossolo nos sistemas plantio direto e convencional no primeiro ano. Porto Alegre : UFRGS, 1996. 87 p. Dissertação de Mestrado.

TEDESCO, M. J.; GIANELLO, C.; BISSANI, C. A.; BOHNEN, H.; VOLKWEISS, S. J. Análise de solo, plantas e outros materiais. 2. ed. Porto Alegre : UFRGS, 1995. 174 p. (Boletim Técnico, 5).

ZANCANARO, L. Reatividade de partículas de calcário e influência das composições granulométricas na neutralização da acidez do solo. Porto Alegre : UFRGS, 1996. 127 p. Dissertação de Mestrado. 